\title{
Pengaruh Penggunaan Lembar Kerja Siswa (LKS) Eksperimen Laju Reaksi Berbasis Inkuiri Terbimbing Terhadap Hasil Belajar Siswa Kelas XI MIA SMAN 4 Padang
}

\author{
Margarita Claudya Maida ${ }^{1)}$ Bayharti $^{2)}$ Andromeda $^{3)}$ \\ 1) Prodi Pendidikan Kimia, FMIPA Universitas Negeri Padang \\ ${ }^{2)}$ Jurusan Kimia, FMIPA Universitas Negeri Padang \\ ${ }^{2)}$ Jurusan Kimia, FMIPA Universitas Negeri Padang \\ mclaudyamaida@gmail.com
}

\begin{abstract}
This study aims to reveal the effect of using guided inquiry based experiment worksheet on reaction rate topic on students' learning outcome. This research is a quasi-experimental research, using randomized Posttest Only Control Group Design. The research sample consisted of two classes, namely the experiment class and control class obtained through cluster sampling technique. The population were students of class XI MIA SMAN 4 Padang as much as 6 classes, the academic year 2015/2016. Sample were class XI MIA 1 (experimental group) and class XI MIA 3 (control group). Learning outcome ware collected by tests at the end of the study. Data analysis showed that the experiments class learning with guided inquiry based experiment worksheet got learning outcome with average value of 86.27. Meanwhile learning outcomes of student in control class who learned without guided inquiry based experiment worksheet was 74.40. Both of Normality and Homogenous's results showed that the distribution of the two experimental classes were normal and homogeneous. After the $t$-test on the real level of 0.05 was found that $t_{\text {count }}$ is greater than $t_{\text {table. }}$ It's means that research hypothesis $\left(H_{1}\right)$ is accepted, so that it can be concluded that the results of student learning using student worksheet guided inquiry-based reaction rate is significantly higher than the student worksheet without a reaction rate-based guided inquiry.
\end{abstract}

Keywords : Guided Inquiry, Student Worksheet Experiment, Rate of reaction

is is an open access article distributed under the Creative Commons 4.0 Attribution License, which permits unrestricted use, distribution, and reproduction in any medium, provided the original work is properly cited. $@ 2018$ by author and Universitas Negeri Padang.

\section{PENDAHULUAN}

Laju reaksi merupakan salah satu materi yang diajarkan di kelas XI tingkat SMA/MA. Pada materi ini siswa harus mampu menjelaskan faktor-faktor yang mempengaruhi laju reaksi yaitu konsentrasi, luas permukaan, suhu dan katalis, serta mampu menghitung dan menentu kan orde reaksi, persamaan laju reaksi dan tetapan laju reaksi melalui percobaan (KD 4.6 dan 4.7 Laju Reaksi Kurikulum 2013, Kemendikbud, 2013). Dalam penyampaian konsep laju reaksi, sesuai dengan KD di atas maka pembelajaran materi ini membutuhkan kegiatan praktikum. Kegiatan praktikum ber guna agar siswa dapat menemukan konsep yang terdapat pada materi laju reaksi. Sesuai dengan anjuran Kurikulum 2013, dimana peserta didik bukan lagi sebagai objek pembelajaran tetapi juga sebagai subjek pembelajaran, maka keberadaan praktikum sebagai metode pembe lajaran bidang studi sains merupakan suatu keharusan.

Berdasarkan hasil observasi dan tanya jawab dengan beberapa guru kimia dan beberapa orang siswa SMA Negeri 4 Padang diperoleh informasi bahwa kegiatan praktikum dilakukan setelah pembelajaran teori sehingga praktikum cendrung bersifat mengkonfirmasi konsep yang telah diperoleh. Selain itu, siswa melakukan praktikum sesuai dengan instruksi yang terdapat dalam buku teks tanpa memikirkan alasan pengerjaan tahap demi tahap yang dilakukan dan belum dapat menuntun siswa menemukan konsep sendiri. Jika hal ini terjadi terus menerus maka kegiatan pratikum hanya menjadi kegiatan mengumpulkan data. Oleh sebab itu diperlukan suatu penuntun yang dapat membimbing siswa untuk menemukan konsep sendiri dan membuat kegiatan pratikum menjadi lebih bermakna. Teori belajar Piaget menegaskan bahwa 
pengetahuan akan mempunyai makna jika dicari dan diselidiki secara mandiri oleh siswa (Hartono, 2013).

Dalam pelaksanaan praktikum diperlukan suatu penuntun yang dapat membimbing siswa dalam kegiatan pratikum supaya lebih terarah. Salah satunya adalah penuntun praktikum dalam bentuk LKS eksperimen berbasis inkuiri terbimbing. Penelitian yang telah dilakukan oleh Kholifudin dan Yasin (2012) menyatakan model inkuiri terbimbing melalui eksperimen memberi kan keleluasaan pada siswa untuk melakukan percobaan sendiri dengan bimbingan guru sehingga siswa mempunyai keinginan yang lebih besar untuk menemukan konsep. Proses pembelajaran dengan menggunakan model inkuiri terbimbing dapat mengembangkan dan meningkatkan keterampilan proses sains dan hasil belajar siswa (Saputra dkk, 2012).

LKS eksperimen berbasis inkuiri terbim bing dilengkapi materi ajar yang berisi orientasi (menghubungkan pengetahuan baru dengan pengetahuan sebelumnya) dan pertanyaan kunci (critical thinking questions) yang menuntun siswa untuk menemukan konsep yang sedang dipelajari. Model inkuiri terbimbing melibatkan siswa secara langsung dalam proses pembe lajaran melalui penyelidikan dari permasalahan yang diberikan guru, kemudian siswa menentu kan proses dan solusi dari permasalahan tersebut hingga akhirnya siswa dapat menemukan konsep sendiri dan dapat membuat kesimpulan. Pembe lajaran menggunakan model inkuiri terbimbing terdiri dari 5 tahap yaitu orientasi, eksplorasi, penemuan konsep atau pembentukan konsep, aplikasi dan penutup (Hanson, 2005).

Orientasi merupakan tahap mempersiap kan siswa untuk belajar. Pada tahap ini guru dapat memberikan motivasi untuk menciptakan minat dan rasa ingin tahu siswa. Untuk membangun pengetahuan baru, siswa harus menghubungkan materi yang akan dipelajari dengan pengetahuan awal sebelum mempelajari materi laju reaksi (prior knowledge), sehingga proses pembelajaran akan terasa lebih bermakna karena adanya ketertarikan dan kayakinan mengenai pentingnya topik laju reaksi (Hanson, 2005). Pengetahuan awal merupakan pengetahuan yang telah ada sebelum pelaksanaan tugas belajar tertentu, tersedia atau dapat dipanggil kembali atau direkonstruksi dan relevan untuk pencapaian tujuan pembelajaran.

Pada tahap eksplorasi siswa diberikan sebuah model untuk mengembangkan pema- haman mereka tentang konsep laju reaksi Model dapat berupa diagram, grafik, data hasil eksperimen, persamaan, metodologi, beberapa prosa, simulasi komputer dan demonstrasi (Hanson, 2006). Pada tahap ini siswa memiliki kesem patan untuk melakukan pengamatan, merancang eksperimen, mengumpulkan dan menganalisa data atau informasi, mengusulkan, menanyakan dan menguji hipotesis (Hanson, 2005). Setiap konsep dieksplorasi dengan satu atau lebih model atau data hasil percobaan yang telah dilakukan oleh siswa dan dipandu dengan pertanyaan kunci (critical thinking question). Pertanyaan kunci adalah pertanyaan yang membimbing siswa menganalisis model dan menemukan konsep sendiri. Pertanyaan kunci disusun dari yang sederhana hingga yang sulit. Sehingga di akhir pertanyaan kunci siswa akan dapat menemukan konsep.

Pada tahap eksplorasi siswa secara efektif dipandu dan didorong untuk mengeskplorasi model, kemudian menarik kesimpulan dan membuat prediksi. Setelah siswa terlibat dalam tahap pembentukan konsep, informasi tambahan dan nama konsep dapat diperkenalkan. Tahap eksplorasi dan pembentukan konsep bersamasama membantu siswa untuk mengembangkan dan memahami konsep yang dipelajari.

Tahap aplikasi merupakan tahapan pemberian latihan dan soal. Latihan memberi kesempatan kepada siswa untuk membangun kepercayaan diri dalam situasi sederhana dan konteks yang dikenal. Disisi lain, soal membutuhkan siswa untuk menganalisis situasi yang kompleks, untuk mentransfer pengetahuan baru pada konteks yang tidak dikenal, untuk mensintesisnya dengan pengetahuan lain, dan untuk menggunakannya dalam cara-cara baru dan berbeda (Hanson, 2006).

Pada tahap penutup siswa dapat membuat kesimpulan dan memahami konsep yang dipelajari serta menghubungkan antara satu konsep dengan konsep yang lainnya. Penilaian dapat diperoleh dengan melaporkan hasilnya kepada rekan-rekan dan guru. Pada penggunaan LKS berbasis inkuiri terbimbing ini guru merupakan fasilitator dalam penyelidikan yang mendorong siswa mengungkapkan atau menjawab pertanyaan-pertanyaan juga membimbing siswa untuk penyelidikan lebih lanjut. Sedangkan siswa akan dihadapkan pada tugas-tugas yang relevan untuk diselesaikan baik melalui diskusi kelompok maupun secara individual agar mampu menyelesaikan masalah dan menarik suatu kes- 
impulan secara mandiri maupun berkelompok (Iryani dkk, 2016).

LKS yang digunakan dalam penelitian ini disusun oleh Iwefriani pada tahun 2015 yang telah memenuhi uji validitas, praktikalitas dan belum pernah di uji cobakan pengaruhnya terhadap hasil belajar (Andromeda dkk, 2017). LKS tersebut berisi tentang materi laju reaksi yang diajarkan dikelas XI tingkat SMA/MA. Penelitian ini bertujuan untuk mengungkapkan pengaruh penggunaan LKS eksperimen laju reaksi berbasis inkuiri terbimbing terhadap hasil belajar siswa di kelas XI MIA SMAN $4 \mathrm{~Pa}-$ dang.

\section{METODE PENELITIAN}

Jenis penelitian ini adalah eksperimen semu dengan desain penelitian adalah Rando mized Control Group Posttest Only Design. Pada desain penelitian ini terdapat dua kelas yang masing-masing dipilih secara random (R), yaitu kelas eksperimen dan kelas kontrol. Kelas eksperimen dalam pembelajaran menggunakan LKS (Lembar Kerja Siswa) eksperimen berbasis inkuiri terbimbing, sedangkan kelas kontrol menggunakan LKS yang disediakan sekolah. Pengaruh adanya perlakuan (treatment) adalah $\mathrm{X}_{1}$ dengan $\mathrm{X}_{2}$. Desain penelitian ini dapat dilihat pada Tabel 1.

Tabel 1. Desain Penelitian

\begin{tabular}{|lcc|}
\hline \multicolumn{1}{|c}{ Sampel } & Perlakuan & Tes akhir \\
\hline Kelas Eksperimen & $\mathrm{X}_{1}$ & $\mathrm{O}$ \\
\hline Kelas Kontrol & $\mathrm{X}_{2}$ & $\mathrm{O}$ \\
\hline
\end{tabular}

(Sugiyono, 2012)

Keterangan : $X_{1}=$ pembelajaran menggunakan lembar kerja siswa eksperimen berbasis inkuiri terbimbing, $\mathrm{X}_{2}=$ pembelajaran menggunakan lembar kerja siswa yang disediakan sekolah, $\mathrm{O}=$ tes akhir

\section{Populasi dan Sampel}

Populasi

Populasi adalah objek atau subjek yang telah tergeneralisasi yang mempunyai kualitas dan karakteristik tertentu yang ditetapkan oleh peneliti untuk diteliti (Sugiyono, 2012). Populasi dalam penelitian ini adalah seluruh siswa kelas XI MIA (6 kelas) SMAN 4 Padang pada tahun ajaran 2015/2016.

\section{Sampel}

Sampel adalah sebagian kecil dari populasi yang dijadikan wakil dalam penelitian (Winarsunu, 2009). Dengan menggunakan teknik pengambilan sampel cluster sampling menurut Gay (2000) didapatkan kelas sampel pada penelitian ini adalah kelas XI MIA 1 sebagai kelas eksperimen dan XI MIA 3 sebagai kelas kontrol.

\section{Variabel dan Data}

Variabel

Variabel dalam penelitian ini terdiri dari variablel terikat, variabel bebas, dan variabel kontrol. Pada penelitian ini yang merupakan variabel terikat yaitu hasil belajar siswa yang diperoleh setelah melakukan tes akhir. Sedang kan variabel bebas yaitu perlakuan berupa pembelajaran dengan menggunakan LKS ekspe rimen laju reaksi berbasis inkuiri terbimbing yang diberikan kepada siswa kelas eksperimen. Sebagai variabel kontrol yaitu segala sesuatu yang bisa mempengaruhi hasil belajar siswa. Hal ini dapat berupa alokasi waktu, materi, kuri kulum dan guru yang mengajar dikelas sampel.

Data

Jenis data pada penelitian ini adalah data primer yang diperoleh dari tes hasil belajar yang diberikan perlakuan pada kelas sampel.

\section{Prosedur Penelitian}

Penelitian dilakukan dalam 3 tahap yaitu, tahap persiapan, tahap pelaksanaan dan tahap penyelesaian. Pada tahap persiapan dilakukan pembuatan RPP, uji coba soal dan analisis soal. Soal yang diuji-cobakan berjumlah 35 soal, dengan bentuk objektif. Setelah dilakukan uji coba dan analisis soal didapatkan 25 soal yang layak digunakan sebagai tes akhir. Pada tahap pelaksanaan dilakukan kegiatan pembelajaran. Pengujian tes akhir dan pengolah an data tes akhir dan data pengamatan dilakukan pada tahap penyelesaian.

\section{Instrumen Penelitian}

Instrumen yang dipakai dalam penilitian ini adalah tes tertulis untuk penilaian hasil belajar. Tes yang digunakan berupa soal objektif yang disesuaikan dengan tujuan pembelajaran.

\section{Teknik Analisis Data}

Analisis terhadap data penelitian dilaku kan bertujuan untuk menguji kebenaran hipo 
tesis yang diajukan dalam penelitian. Untuk menganalisis kebenaran data hasil penelitian digunakan uji hipotesis yaitu dengan uji perbedaan dua rata-rata atau uji-t. Sebelum melakukan uji-t terlebih dahulu dilakukan uji normalitas dan uji homogenitas.

Uji Normalitas

Uji normalitas bertujuan untuk melihat apakah populasi terdistribusi normal atau tidak. Untuk menguji normalitas digunakan uji Liliefors (Sudjana, 2005).

Uji Homogenitas

Untuk menentukan apakah kedua kelom pok data mempunyai varians yang homogen dilakukan uji homogenitas dengan mengguna kan rumus :

$$
\mathrm{F}=\frac{s_{1}^{2}}{s_{2}^{2}}
$$

Keterangan $: \mathrm{F}=$ perbandingan antara varians terbesar dengan varians terkecil, $S_{1}=$ varians hasil belajar terbesar, $S_{2}=$ varians hasil belajar terkecil

\section{Uji hipotesis}

Uji hipotesis bertujuan untuk menetukan apakah hipotesis penelitian dapat diterima atau ditolak. Hipotesis tersebut ditulis dalam bentuk hipotesis statistik dengan uji satu pihak yaitu

$$
\begin{aligned}
& \text { Ho: } \mu_{1}=\mu_{2} \\
& \mathrm{H}_{1}: \mu_{1}>\mu_{2}
\end{aligned}
$$

Keterangan : $\mu_{1}=$ Skor rata- rata kelas eksperimen, $\mu_{2}=$ Skor rata- rata kelas kontrol

Berdasarkan hasil pengolahan data diperoleh bahwa kedua kelas mempunyai nilai terdistribusi normal dan mempunyai varians yang homogen. Oleh karena itu untuk menguji hipotesis digunakan uji $t$, dengan persamaan sebagai berikut ini

$$
\mathrm{t}=\frac{\overline{x_{1}-\overline{x_{2}}}}{s \sqrt{\frac{1}{\bar{n}_{1}}+\frac{1}{n_{2}}}}
$$

Keterangan : $\mathrm{x}_{1}=$ Nilai rata-rata siswa kelas eksperimen, $\mathrm{x}_{2}=$ Nilai rata-rata siswa kelas kontrol, $\mathrm{s}=$ Simpangan baku, $\mathrm{n}_{1}=$ Jumlah siswa kelas eksperimen, $\mathrm{n}_{2}=$ Jumlah siswa kelas kontrol.

\section{HASIL DAN PEMBAHASAN}

\section{Deskripsi Data}

Data yang diperoleh berupa hasil belajar siswa pada ranah kognitif dari 30 siswa dari setiap kelas eksperimen dan kelas kontrol. Ratarata yang didapatkan untuk kelas eksperimen dan kelas kontrol berturut-turut adalah 86,27 dan 74,40 .

\section{Analisis Data}

Analisis data dilakukan dengan cara berurutan, mulai dari melihat perbedaan nilai kelas eksperimen dan kelas kontrol, uji normalitas, uji homogenitas dan uji-t. Nilai hasil belajar siswa pada kelas eksperimen dan kelas kontrol, sehingga diperoleh nilai rata-rata $(\bar{x})$, simpangan baku $(\mathrm{S})$, dan varians $\left(\mathrm{S}^{2}\right)$. Seperti terlihat pada Tabel 2 .

Tabel 2. Nilai Rata-Rata, Simpangan Baku, dan Varians Kelas Eksperimen dan Kelas Kontrol

\begin{tabular}{|c|c|c|c|c|}
\hline Kelas & $\mathrm{N}$ & $\bar{X}$ & $S$ & $S^{2}$ \\
\hline Eksperimen & 30 & 86,27 & 7,10 & 50,41 \\
\hline Kontrol & 30 & 74,40 & 9,55 & 91,14 \\
\hline
\end{tabular}

Dari Tabel 2 terlihat bahwa hasil belajar siswa kelas eksperimen lebih tinggi dari pada kelas kontrol. Untuk mengetahui apakah terdapat pengaruh signifikan penggunaan LKS laju reaksi berbasis inkuiri terbimbing maka dilakukan uji hipotesis. Uji hipotesis didasarkan pada uji normalitas dan homogenitas pada kedua kelas sampel. Analisis uji normalitas dirangkum pada Tabel 3.

Tabel 3. Hasil Uji Normalitas terhadap Tes Akhir Kelas Sampel

\begin{tabular}{|c|c|c|c|c|c|}
\hline Kelas & $\alpha$ & $\mathrm{N}$ & $L_{o}$ & $L_{t}$ & Distribusi \\
\cline { 1 - 4 } Eksperimen & \multirow{2}{*}{0,05} & 30 & 0,1052 & 0,161 & Normal \\
\cline { 1 - 4 } Kontrol & & 30 & 0,1288 & 0,161 & Normal \\
\hline
\end{tabular}

Dari Tabel 3 diketahui harga $\mathrm{L}_{0}$ pada masing-masing kelas sampel lebih kecil daripada harga $L_{t}$ nya. Hal ini menunjukkan bahwa kedua kelas sampel terdistribusi normal pada semua kompetensi.

Untuk menentukan kedua kelas sampel memiliki varian yang homogen atau tidak dilakukan uji homogenitas. Hasil analisis uji homogenitas dirangkum pada Tabel 4. 
Tabel 4. Hasil Uji Homogenitas terhadap Hasil Tes Akhir Kelas Sampel

\begin{tabular}{|c|c|c|c|c|c|}
\hline Kelas & $\mathrm{N}$ & $\mathrm{S}^{2}$ & $F_{h}$ & $F_{t}$ & Keterangan \\
\hline Eksperimen & 30 & 50,41 & \multirow{2}{*}{1,81} & \multirow{2}{*}{1,84} & \multirow{2}{*}{ Homogen } \\
\hline Kontrol & 30 & 91,14 & & & \\
\hline
\end{tabular}

Dari Tabel 4 diketahui harga $F_{h}$ pada masing-masing kelas sampel lebih kecil daripada harga $F_{\mathrm{t}}$. Hal ini menunjukkan bahwa kedua kelas sampel memiliki varians yang homogen pada semua kompetensi.

Hasil uji normalitas dan uji homogenitas kedua kelasmenunjukkan bahwa kedua kelas terdistribusi normal dan mempunyai varians yang homogen. Oleh karena itu untuk menguji hipotesis digunakan uji $\mathrm{t}$ dan data hasil uji hipotesis terangkum pada Tabel 5.

Tabel 5. Hasil Uji Hipotesis terhadap Hasil Tes Akhir Kelas Sampel

\begin{tabular}{|c|c|c|c|c|c|}
\hline Kelas & $\mathrm{N}$ & Rata-rata & $S^{2}$ & $t_{h}$ & $t_{t}$ \\
\hline Eksperimen & 30 & 86,27 & 50,41 & \multirow{2}{*}{5,47} & \multirow{2}{*}{1,67} \\
\hline Kontrol & 30 & 74,40 & 91,14 & & \\
\hline
\end{tabular}

Berdasarkan analisis yang telah dilakukan didapatkan $t_{\text {hitung }}>t_{\text {tabel}}$, sehingga $\mathrm{H}_{0}$ ditolak pada taraf nyata 0,05 . Hal ini menunjukkan bahwa hasil belajar siswa dengan menggunakan LKS eksperimen laju reaksi berbasis inkuiri terbimbing lebih tinggi secara signifikan daripada hasil belajar siswa yang menggunakan LKS yang bukan berbasis inkuiri terbimbing.

\section{Pembahasan}

Pada pembelajaran laju reaksi di kelas eksperimen dan kontrol sama-sama digunakan model pembelajaran inkuiri terbimbing. Model pembelajaran inkuiri terbimbing merupakan model pembelajaran yang berpusat pada siswa, siswa bekerja dalam kelompok-kelompok kecil dengan peran individu untuk memastikan bahwa semua siswa terlibat penuh dalam proses pembelajaran yang membuat siswa lebih mengerti dan mengingat lebih lama (Straumanis, 2010). Model pembelajaran inkuiri terbimbing terdiri dari 5 tahap, yaitu orientasi, eksplorasi, pembentukan konsep, aplikasi dan penutup (Hanson, 2005). Hal yang membedakan kelas eksperimen dan kelas kontrol adalah LKS yang digunakan. Pada kelas ekperimen digunakan LKS eksperi- men berbasis inkuiri terbimbing, yang telah diujicobakan dan ditentukan nilai validitas dan praktikalitasnnya oleh Andromeda (2017) sedangkan pada kelas kontrol digunakan LKS yang biasa digunakan sekolah.

Pembelajaran dengan menggunakan LKS berbasis inkuiri terbimbing dapat menarik minat siswa dalam belajar. Hal ini disebabkan karena LKS berbasis inkuiri terbimbing memuat orientasi atau pengetahuan prasyarat, informasi dan model berupa data hasil percobaan, gambar, tabel, pertanyaan kunci, dan latihan. Selain itu terdapat model berupa gambar disertai dengan warna yang dapat menarik minat siswa dalam belajar. Dalam hal tersebut, siswa mengamati dan menganalisis model dari hasil pengamatan dan melakukan percobaan untuk menjawab pertanyaan yang dapat mendorong siswa untuk berpikir kritis dan analitis. Pertanyaan tersebut disebut dengan pertanyaan kunci atau critical thingking-question.

Pertanyaan kunci merupakan jantung dari kegiatan inkuiri terbimbing (Hanson, 2005). Pertanyaan kunci merupakan pertanyaaan yang menuntun siswa untuk berpikir kritis, analitis, sehingga dapat membantu siswa untuk membangun konsep sendiri, dan membuat kesimpulan (Kholifudin \& Yasin, 2012). Pertanyaan-pertanyaan ini dibuat saling berhubungan satu sama lain dari tingkat rendah hingga tingkat tinggi sehingga siswa dapat mengembangkan jawaban dengan memikirkan tentang apa yang mereka temukan dalam model/informasi, apa yang mereka sudah tahu dan apa yang telah mereka pelajari dengan menjawab macammacam pertanyaan sebelumnya.

Berbeda halnya dengan LKS yang digunakan di kelas kontrol. Pada LKS tersebut tidak terdapat pertanyaan kunci melainkan pertanyaan yang sifatnya mengkonfirmasi hasil percobaan, pertanyaan-pertanyaan yang tidak saling berhubungan satu sama lain, pertanyaan yang tidak membimbing siswa dalam menemukan suatu konsep, sehingga siswa akan kesulitan dalam membangun pemahaman konsep.

Dengan adanya LKS eksperimen berbasis inkuiri terbimbing yang digunakan dalam sistem belajar kelompok, siswa bekerja sama dalam membangun pemahaman dan pengetahuannya, sehingga siswa lebih mudah mengingat dan mengerti (Hanson, 2006). Hal ini terlihat ketika siswa menjawab pertanyaan kunci. Siswa bekerja sama dan berdiskusi dalam men- 
jawab pertanyaan kunci. Dengan demikian pembelajaran menjadi lebih efektif. Hal tersebut sesuai dengan pendapat Hanson (2005), yang mengemukakan bahwa "pembelajaran menjadi lebih efektif ketika siswa saling bekerja sama dengan banyak berdiskusi baik didalam kelompok maupun antar kelompok".

Siswa dengan menggunakan LKS eksperimen berbasis inkuiri terbimbing, belajar sambil melakukan sendiri dalam menemukan konsep yang dipelajari, siswa akan memperoleh pengalaman lebih bermakna dan melekat dalam pikiran mereka (Andromeda dkk, 2016). Dengan kuatnya informasi yang melekat pada memori siswa, akan berdampak pula terhadap perolehan hasil belajar siswa. Disamping itu, siswa dapat belajar memecahkan masalah secara obyektif, kritis, terbuka dan kerja sama. Hal ini akan memberikan pengaruh terhadap sikap ilmiah, keterampilan serta hasil belajar siswa (Dewi dkk, 2013)

Pada kelas eksperimen, ketika siswa mengerjakan latihan dan menyampaikan hasil diskusi (saat konfirmasi dari guru), siswa terlihat antusias dalam mengemukakan kesimpulan kelompoknya. Hal tersebut sesuai dengan penelitian sebelumnya yang dilakukan oleh Bilgin dan Myers disimpulkan bahwa siswa yang belajar dengan menggunakan model pembelajaran inkuiri terbimbing lebih mudah mengerti dan memahami konsep pelajaran serta meningkatkan efektivitas interaksi, membangun tim, pembelajaran dan minat melalui kerja kelompok yang sangat terstruktur Bilgin (2009) serta Myers dan Richard (2012) yang menyimpulkan bahwa siswa yang belajar dengan menggunakan model pembelajaran inkuiri terbimbing lebih mudah mengerti dan memahami konsep pelajaran serta meningkatkan efektivitas interaksi, membangun tim, pembelajaran dan minat melalui kerja kelompok yang sangat terstruktur.

Tingginya hasil belajar siswa pada kelas eksperimen secara signifikan dibandingkan hasil belajar siswa pada kelas kontrol juga terlihat pada kompetensi afektif dan psikomotor. Hal ini disebabkan karena penggunaan LKS eksperimen berbasis inkuiri terbimbing dalam proses pembelajaran, memberi peluang kepada siswa untuk berpartisipasi lebih aktif dalam proses belajar dibandingkan kelas kontrol. Dalam pembelajaran, siswa aktif dalam melakukan pengamatan, mengolah data dan menjawab pertanyaanpertanyaan kunci. Silberman (2006) menyatakan bahwa dalam belajar aktif, siswa akan mengupayakan sesuatu, dia mencari jawaban atas sebuah pertanyaan, memerlukan informasi untuk memecahkan masalah, atau menyelidiki cara untuk melakukan pekerjaan (Silberman, 2006). Keterlibatan siswa secara aktif ini akan berdampak baik pada hasil belajar siswa, afektif siswa dan psikomotor siswa.

LKS eksperimen berbasis inkuiri terbimbing memberikan bimbingan melalui model, pertanyaan kunci, latihan dan pemecahan masalah. Hal ini membuat kelas ekperimen memiliki beberapa kelebihan dari kelas kontrol yaitu sebagai berikut; 1) Membuat siswa kelas eksperimen lebih aktif dari kelas kontrol, sebab peserta didik dituntut untuk menyelesaikan masalah sendiri dengan bantuan pertanyaan kunci, 2) Memiliki kemapuan berpikir kristis dan analistis siswa yang lebih baik dari kelas control, 3) Memiliki prestasi akademik yang lebih tinggi dari kelas kontrol.

\section{KESIMPULAN}

Berdasarkan hasil penelitian dan analisis data yang telah dilaksanakan disimpulkan bahwa terdapat penggaruh penggunaan LKS ekspe rimen laju reaksi berbasis inkuiri terbimbing terhadap hasil belajar siswa. Diperoleh hasil belajar kelas eksperimen (menggunakan LKS eksperimen berbasis inkuiri terbimbing) lebih tinggi dengan rata-rata 86,27 dibandingkan dengan kelas kontrol (LKS yang biasa diguna kan sekolah) dengan rata-rata 74,40.

\section{DAFTAR PUSTAKA}

Andromeda, A., Bahrizal, B., \& Ardina, Z. 2016. Efektifitas Kegiatan Praktikum Terintegrasi dalam Pembelajaran pada Materi Kesetimbangan Kimia Kelas XI SMA/MA. EKSAKTA, 1, 45-51.

Andromeda, A., Yerimadesi, Y., \& Iwefriani, I. 2017. Pengembangan Lembaran Kerja Siswa (LKS) Eksperimen Berbasis GuidedInquiry Materi Laju Reaksi Untuk Siswa SMA/MA. JURNAL EKSAKTA PENDIDIKAN (JEP), 1(1), 47-54. doi:10.24036/ jep/vol1-iss $1 / 47$

Bilgin, Ibrahim. 2009. The Effects of Guided Inqury Instruction Incorporating, a Cooperative Learning Approach on University Stu- 
dents'Achievement of Acid and Bases Concepts and Attitude Toward Guided Inqury Instruction. SRE, 4 (10): 1038-1046.

Dewi, N. L., Dantes, N., \& Sadia, I. W. 2013. Pengaruh model pembelajaran inkuiri terbimbing terhadap sikap ilmiah dan hasil belajar IPA. PENDASI: Jurnal Pendidikan Dasar Indonesia, 3(1).

Gay, R L, dkk. 2000. Educational Research: Competencies for Analysis and Applications. New Jersey: Pearson

Hanson, D. 2005. Designing Process-Oriented Guided-Inquiry Activities. New York: Pasific Crest.

Hartono, Rudi. 2013. Ragam Model Mengajar yang Mudah Diterima Murid. Jogja karta: DIVA Press.

Iryani, I., Mawardi, M., \& Andromeda, A. 2016. Pengaruh Penggunaan Lks Berbasis Inkuiri Terbimbing Terhadap Hasil Belajar Siswa Untuk Materi Koloid Kelas Xi Sman $1 \mathrm{Ba}-$ tusangkar. EKSAKTA, 1, 82-89.

Kholifudin, M.Yasin. 2012. Pembelajaran Fisika dengan Inkuiri Terbimbing melalui Metode Eksperimen dan Demonstrasi Ditinjau dari Gaya Belajar Siswa. Laporan Penelitian. Prosiding Pertemua Ilmiah XXVI HFI Jateng \& DIY.

Myers, Trina and Richard, Monypenny. 2012. Overcoming The Glassy-Eyed Nod: An Application of Process-Oriented Guided Inquiry Learning Techniques In Information Technology. Journal of Learning Design, $5(1)$.

Saputra, Alanindra, Widoretno, Sri dan Santosa, Slamet. 2012. Peningkatan Keterampilan Proses Sains dan Hasil Belajar Siswa melalui Penerapan Strategi Guided Inquiry di SMP Negeri 5 Surakarta Kelas VIII F Tahun Pelajaran 2011/ 2012. BIO-PEDAGOGI , 1 (1). pp. 36-45. ISSN 2252-6897

Saputra, A. 2012. Peningkatan Keterampilan Proses Sains dan Hasil Belajar Siswa melalui Penerapan Strategi Guided Inquiry di SMP Negeri 5 Surakarta Kelas VIII F Tahun Pelajaran 2011/ 2012. Jurnal Oktober 2012, 1, No.1, Hal 36-45. Surakarta.

Silberman, Mel. 2006. Active Learning 101 Cara Belajar Siswa Aktif. Penerjemah: Raisul Muttaqien. Bandung: Nusa media
Straumanis, Andrei. 2010. Process Oriented Guided Inquiry Learning. A Practical Guide For Instruktor, Organic Chemistry: Guided Inquiry, Second Edition. USA: Brool/Cole.

Sudjana. 2005. Metode Statistik. Bandung: Tarsito

Sugiyono. 2012. Metode Penelitian (Pendekatan Kuantitatif, Kualitatif, dan $R \& D)$ ). Bandung: Alfabeta.

Winarsunu. Tulus. 2009. Statistik dalam Penelitian Psikologi dan Pendidikan. Malang: UMM Press. 